\title{
Evaporation-Induced Self-Assembly of Hybrid Bridged Silsesquioxane Film and Particulate Mesophases with Integral Organic Functionality
}

Yunfeng Lu*, Hongyou Fan ${ }^{\dagger}$ Nilesh Doke ${ }^{\dagger}$, Douglas A. Loy*, Roger A. Assink*, David A. LaVan*, and C.Jeffrey Brinker* ${ }^{\dagger}$

*Sandia National Laboratories, Albuquerque, NM 87185

†The University of New Mexico Department of Chemical and Nuclear Engineering and UNM/NSF Center for Micro-Engineered Materials, Albuquerque, NM 87131.

Since the discovery of surfactant-templated silica mesophases ${ }^{1}$, the development of organic modification schemes to impart functionality to the pore surfaces has received much attention $2-13$. Most recently, using the general class of compounds referred to as

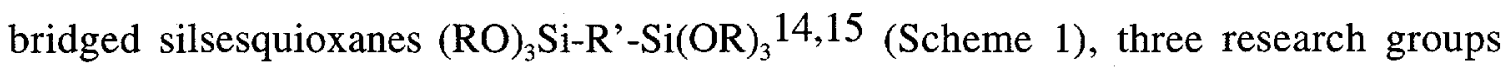
have reported the formation of a new class of poly(bridgedsilsesquioxane) mesophases BSQMS with integral organic functionality $16-19$. In contrast to previous hybrid mesophases where organic ligands or molecules are situated on pore surfaces, this class of materials necessarily incorporates the organic constituents into the framework as molecularly dispersed bridging ligands. Although it is anticipated that this new mesostructural organization should result in synergistic properties derived from the molecular scale mixing of the inorganic and organic components, few properties of $B S Q M s$ have been measured. In addition samples prepared to date have been in the form of granular precipitates, precluding their use in applications like membranes, fluidics, and low $k$ dielectric films needed for all foreseeable future generations of microelectronics. Here we use an evaporation-induced self-assembly procedure ${ }^{20}$ to prepare $B S Q M$ films and spherical nanoparticles. Capacitance-voltage measurements along with a variety of 


\section{DISCLAIMER}

This report was prepared as an account of work sponsored by an agency of the United States Government. Neither the United States Government nor any agency thereof, nor any of their employees, make any warranty, express or implied, or assumes any legal liability or responsibility for the accuracy, completeness, or usefulness of any information, apparatus, product, or process disclosed, or represents that its use would not infringe privately owned rights. Reference herein to any specific commercial product, process, or service by trade name, trademark, manufacturer, or otherwise does not necessarily constitute or imply its endorsement, recommendation, or favoring by the United States Government or any agency thereof. The views and opinions of authors expressed herein do not necessarily state or reflect those of the United States Government or any agency thereof. 


\section{DISCLAIMER}

Portions of this document may be illegible in electronic image products. Images are produced from the best available original document. 
structural characterization procedures were performed to begin to elucidate structureproperty relationships of this new class of thin film and particulate mesophases.

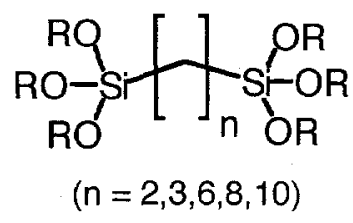

$\underline{1}$

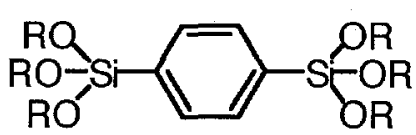

$\underline{2}$

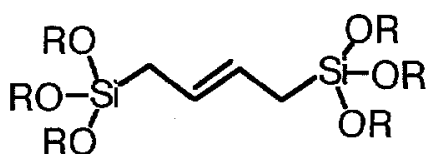

$\underline{\mathbf{3}}$

Scheme 1. Chemical formulae of bridged silsesquioxane monomers 1- $\underline{3}$.

The initially reported syntheses of $B S Q M S$ involved precipitation in basic aqueous media followed by aging for periods up to several days. In order to form homogeneous films, precipitation must be avoided, and the self-assembly process must be accomplished within the brief time span of the dip- or spin-coating operation (at most several seconds). To meet these requirements, we prepare dilute, homogeneous, ethanolic solutions that suppress silica/surfactant self-assembly and employ acidic conditions that retard siloxane condensation. In a typical synthesis procedure requisite amounts of $\underline{1}$ (from Gelest and triply-distilled prior to use), $\underline{2}$ (synthesized according to ref. 15) or $\underline{\mathbf{3}}$ (synthesized according to ref. 15$)^{21}$ are dissolved in ethanol followed by addition of $1-8 \mathrm{wt} \%$ surfactant: cationic (CTAB: $\mathrm{CH}_{3}\left(\mathrm{CH}_{2}\right)_{15} \mathrm{~N}^{+}\left(\mathrm{CH}_{3}\right)_{3} \mathrm{Br}$ ), non-ionic (Brij-56: $\mathrm{C}_{16} \mathrm{H}_{33}\left(\mathrm{OCH}_{2} \mathrm{CH}_{2}\right)_{10} \mathrm{OH}$ ), anionic (SDS: $\mathrm{C}_{12} \mathrm{H}_{25} \mathrm{OSO}_{3} \mathrm{Na}^{+}$) or block copolymer (P123: $\left.\mathrm{H}\left(\mathrm{OCH}_{2} \mathrm{CH}_{2}\right)_{20}\left(\mathrm{OCH}\left(\mathrm{CH}_{3}\right) \mathrm{CH}_{2}\right)_{70}\left(\mathrm{OCH}_{2} \mathrm{CH}_{2}\right)_{20} \mathrm{OH}\right)$ and an aqueous solution of $\mathrm{HCl}(0.1-$ $1.0 \mathrm{~N}$ ). The investigated range of starting compositions are represented by the molar ratios $\mathrm{Si}: \mathrm{EtOH}: \mathrm{H}_{2} \mathrm{O}: \mathrm{HCl}$ :surfactant $=1: 22: 5: 0.004: 0.054-0.18$. In order to evaluate the effect of substitution of bridged silsesquioxanes for siloxanes on the properties of resultant thin film mesostructures, a series of films was prepared with varying ratios of 
TEOS and $(\mathrm{EtO})_{3} \mathrm{Si}-\left(\mathrm{CH}_{2}\right)_{2}-\mathrm{Si}(\mathrm{OEt})_{3}$. For this series the starting compositions are represented by the molar ratios TEOS: $1(n=2): E t O H: \mathrm{H}_{2} \mathrm{O}: \mathrm{HCl}:$ surfactant $=(0.3-$ 3):1:0.25:0.044:0.8:0.00084. In all cases the initial surfactant concentration $c_{o} \ll$ the critical micelle concentration $\mathrm{cmc}$, implying mesoscale homogeneity of the starting sols.

Films were prepared by spin- or dip-coating 22 and nanoparticles were prepared by an aerosol-assisted self-assembly process described previously. 23 In both cases preferential ethanol evaporation concentrates the sol in water, non-volatile surfactant, and organically-bridged polysilsesquioxane species. By choosing the initial acid concentration to retard the competing process of siloxane condensation, we exploit the progressively increasing surfactant concentration to drive self-assembly of polysilsesquioxane-surfactant micelles and their further organization into liquid crystalline mesophases. Pre-existing, incipient polysilsesquioxane-surfactant mesostructures (which exist at solid-liquid and liquid-vapor interfaces at $c<c m c$ ) serve to nucleate and orient the mesophase development. 22,23 The result is rapid (several seconds) formation of thin film or particulate $B S Q M s$ that are oriented with respect to the solid-liquid and/or liquid-vapor interfaces. Through variation of the shape of the surfactant along with its charge and initial concentration, this evaporation-induced selfassembly route can be used to attain a range of thin film or particulate mesophases.

Figures $1 \mathrm{a}$ and $\mathrm{b}$ show $\mathrm{x}$-ray diffraction (XRD) results for thin film bridgedpolysilsesquioxane mesophases prepared from the ethylene-bridged silsesquioxane precursor $(1$ with $\mathrm{n}=2$ ) with $\mathrm{CTAB}$, Brij-56, or SDS surfactant before and after calcination at $250^{\circ} \mathrm{C}$ in $\mathrm{N}_{2}$. The multiple sharp peaks observed for the uncalcined SDS system and the virtual elimination of these peaks after calcination are consistent with an 
[001]-oriented lamellar thin film mesophase as is commonly observed for silica thin film mesophases prepared from SDS and TEOS. 24 The CTAB and Brij-56 systems are characterized by single intense peaks that shift slightly to higher $2 \theta$ values (lower $d$ spacing) upon calcination. This behavior is similar to that observed previously for hexagonal and cubic thin film mesophases prepared from TEOS or TEOS plus various organotrialkoxysilane co-monomers. 22,25 In combination with TEM results (discussed below), we interpret the major peak in the CTAB system as the (100) reflection of a 1dimensional hexagonal mesophase with $d=3.4-\mathrm{nm}$. The major XRD peak in the Brij-56 system may be interpreted as a (200) reflection of a cubic mesophase with $a=9.2-\mathrm{nm}$.

TEM micrographs of calcined thin film specimens evaluated by XRD are shown in Figure 2. The striped and hexagonal close-packed textures observed for the $6 \mathrm{wt} \%$ CTAB-derived film (Figure 2a) are characteristic of a 1-dimensional hexagonal mesophase with $d$-spacing $\cong 3.3-3.5-\mathrm{nm}$, consistent with XRD results. Interestingly, we observe undulations and defects in the stripe pattern in a plane normal to the substrate surface, whereas for hexagonal thin film mesophases prepared from TEOS these features are observed only in planes parallel to the substrate surface. ${ }^{22}$ Figure $2 b$ shows the cross-section of the film prepared with $4 \mathrm{wt} \%$ Brij-56. Based on the hexagonal pattern of spots and the 5.3-nm spot-to-spot spacing, we interpret the upper right region as a [111]orientation of a face centered cubic structure with $a \cong 9.1-9.3-\mathrm{nm}$, consistent with XRD results and previous cubic thin film mesophases prepared from Brij-56 and TEOS. 20 Figure $2 \mathrm{c}$ shows the TEM micrograph of a calcined spherical nanoparticle prepared using the phenylene-bridged precursor $\underline{2}$ with 8 wt $\%$ P123 block co-polymer surfactant. Regions adjacent to the particle circumference, which correspond to the thinnest regions 
of the specimen in the imaging direction, exhibit a hexagonal close-packed texture. We interpret this structure as a hexagonal mesophase composed of close-packed cylindrical pore channels aligned parallel to the particle circumference. This orientation arises from the initial nucleation of the hexagonal mesophase at the air-liquid interface and its growth inward driven by an evaporation-induced radial concentration gradient. 23 We note that particles prepared from the comparable TEOS/8wt $\%$ P123 system exhibit a multilamellar vesicular mesostructure. ${ }^{23}$ Figure $2 \mathrm{~d}$ shows the TEM micrograph of calcined spherical nanoparticles prepared using precursor $\mathbf{3}$ with $8 \mathrm{wt} \%$ P123 block copolymer surfactant. This multi-lamellar vesicular structure is composed of concentric bridged polysilsesquioxane layers containing integral vinyl functionality.

The porosity of the thin film specimens prepared from 1 with $6 \mathrm{wt} \% \mathrm{CTAB}$ or $4 w t \%$ Brij-56 was characterized by nitrogen sorption measurements performed on film specimens using a surface acoustic wave (SAW) technique. ${ }^{26}$ The SAW $\mathrm{N}_{2}$ sorption isotherms shown in Figure 3 are qualitatively consistent with those previously obtained for the corresponding TEOS-derived films ${ }^{22}$ and typical of surfactant-templated mesophases in general. Based on a cylindrical pore model, we used the ratio of the thickness-normalized pore volume and surface area to calculate hydraulic pore diameters of 1.8 and $2.5-\mathrm{nm}$, respectively, for the CTAB and Brij-56 films.

Retention of the bridging organic ligands in the calcined specimens was confirmed using ${ }^{13} \mathrm{C}$ and ${ }^{29} \mathrm{Si}$ MAS NMR spectroscopy. For powders prepared from $\underline{\mathbf{1}}$ with $6 \mathrm{wt} \% \mathrm{CTAB}$, we observed a large ${ }^{13} \mathrm{C}$ resonance at $5.2 \mathrm{ppm}$, corresponding to the ethylene bridge, and a very broad ${ }^{29} \mathrm{Si}$ resonance at $-58.5 \mathrm{ppm}$, corresponding to trifunctional (T) silicons. ${ }^{27}$ There was no evidence of tetra-functional Q silicons at -101 or 
$-108 \mathrm{ppm}$, implying complete retention of the bridging ligands. For the phenylenebridged system prepared from $\underline{\mathbf{2}}$ with $8 \mathrm{wt} \% \mathrm{P} 123$, we observed a ${ }^{13} \mathrm{C}$ resonance at 133.4 ppm corresponding to the phenylene bridge and ${ }^{29} \mathrm{Si}$ resonances at -71.0 and $-78.2 \mathrm{ppm}$, corresponding to $\mathrm{T}^{2}$ and $\mathrm{T}^{3}$ species, respectively ${ }^{15}$ (where the superscript denotes the number of bridging oxygens covalently bonded to the tri-functional silicon center). Again, there was no evidence of $Q$ silicons.

To begin to establish structure-porosity relationships, we prepared a series of films from TEOS and $1(\mathrm{n}=2)$ with molar ratios TEOS: $1=75: 25\left(\mathrm{~TB}_{1}\right), 50: 50\left(\mathrm{~TB}_{2}\right)$, and 25:75 $\left(\mathrm{TB}_{3}\right)$. Synthesis and processing procedures were chosen to create isotropic disordered (worm-like) thin film mesophases ${ }^{17}$ with comparable film thicknesses (measured by spectroscopic ellipsometry) and porosities (measured by analyses of SAWbased $\mathrm{N}_{2}$ sorption isotherms). After calcination at $350^{\circ} \mathrm{C}$ under $\mathrm{N}_{2}$ to remove the surfactant templates, all films were vapor-treated with hexamethyldisilazane to avoid water adsorption. Table 1 compares values of the dielectric constants (measured using a standard capacitance-voltage technique employing a mercury probe), Young's modulus and hardness (modulus and hardness calculated from nanoindentation measurements at a constant indentation depth, assuming a Poisson's ratio of 0.2 ). W e observe a consistent trend of increasing modulus and hardness and decreasing dielectric constant with substitution of the bridged silsesquioxane $\left(\equiv \mathrm{Si}-\left(\mathrm{CH}_{2}\right)_{2}-\mathrm{Si} \equiv\right)$ for siloxane ( $\left.\equiv \mathrm{Si}-\mathrm{O}-\mathrm{Si} \equiv\right)$ in the framework. This preliminary evidence suggests that introduction of integral organic groups into the frameworks of mesoporous materials can result in synergistic properties, promising an unprecedented ability to tune properties and function. The trend of 
increasing mechanical performance and decreasing dielectric constant observed here is of immediate and crucial interest to the burgeoning field of low $k$ dielectrics.

\section{Acknowledgements}

This work was supported by the Department of Energy Basic Energy Sciences program, Sandia National Laboratories Lab-Directed Research and Development Program and through a Cooperative Research and Development Agreement with Air Products and Chemicals Incorporated. Sandia National Laboratories is a multi-program laboratory operated by Sandia Corporation, a Lockheed Martin Company, for the U.S. Department of Energy under Contract DE-AC04-94AL85000.

\section{References}

1)Kresge, C.; Leonowicz, M.; Roth, W.; Vartuli, C.; Beck, J. Nature 1992, 359, 710-712.

2)Liu, J.; Feng, X.; Fryxell, G. E.; Wang, L.-Q.; Kim, A. Y.; Gong, M. Adv. Mater. 1998, $10,161-165$.

3)Zhou, W.; Thomas, J. M.; Shephard, D. S.; Johnson, B. F. G.; Ozkaya, D.;

Maschmeyer, T.; Bell, R. G.; Ge, Q. Science 1998, 280, 705-707.

4)Huber, C.; Moller, K.; Bein, T. J. Chem. Soc., Chem. Commun. 1994, 2619-2620.

5)Felipe Diaz, J.; Balkus, J., K.J.; Bedioui, F.; Kurshev, V.; Kevan, L. Chem. Mater. 1997, 9, 61-67.

6)Ogawa, M. Langmuir 1995, 11, 4639-4641.

7)Honma, I.; Zhou, H. S. Adv. Mater. 1998, 10, 1532-1536.

8)Holland, B. T.; Walkup, C.; Stein, A. J. Phys. Chem. B 1998, 102, 4301-4309. 
9)Burkett, S. L.; Sims, S. D.; Mann, S. Chem. Commun. 1996, 1367-1368.

10)Fowler, C.; Burkett, S.; Mann, S. Chem Commun 1997, 1769-1770.

11)Lim, M.; Stein, A. Mat. Res. Soc. Symp. Proc. 1998, 519, 89-93.

12)Fowler, C. E.; Lebeau, B.; Mann, S. Chem. Commun. 1998.

13)Van Rhijn, W. M.; De Vos, D. E.; Sels, B. F.; Bossaert, W. D.; Jacobs, P. A. Chem.

Commun. 1998, 317-318.

14)Loy, D. A.; Jamison, G. M.; Baugher, B. M.; Russick, E. M.; Assink, R. A.; Prabaker, S.; Shea, K. J. J. Non-Cryst. Solids 1995, 186, 44-53.

15)Shea, K. J.; Loy, D. A.; Webster, O. J. Am. Chem. Soc. 1992, 114(17), 6700-10.

16)Inagaki, S.; Guan, S.; Fukushima, Y.; Ohsuna, T.; Terasaki, O. J. Am. Chem. Soc $1999,121,9611-9614$.

17)Melde, B. J.; Holland, B. T.; Blanford, C. F.; Stein, A. Chem. Mater. 1999, 11, 33023308.

18)Asefa, T.; MacLachlan, M. J.; Coombs, N.; Ozin, G. A. Nature 1999, 402, 867-871.

19)Yoshina-Ishii, C.; Asefa, T.; Coombs, N.; MacLachlan, M. J.; Ozin, G. A. Chem.

Commun. 1999, 2539-2540.

20)Brinker, c. J.; Lu, Y.; Sellinger, A.; Fan, H. Adv. Mater. 1999, 11, 579-585.

21)Shaltout, R. M.; Loy, D. A.; Carpenter, J. P.; Dorhourt, K.; Shea, K. J. Polym. Prepr. 1999, 906-907.

22)Lu, Y.; Ganguli, R.; Drewien, C. A.; Anderson, M. T.; Brinker, C. J.; Gong, W. L.;

Guo, Y. X.; Soyez, H.; Dunn, B.; Huang, M. H.; Zink, J. I. Nature 1997, 389, 364-368.

23)Lu, Y.; Fan, H.; Stump, A.; Ward, T. L.; Reiker, T.; Brinker, C. J. Nature 1999, 398, 223-226. 
24)Huang, M. H.; Dunn, B. S.; Soyez, H.; Zink, J. I. Langmuir 1998, 14, 7331-7333. 25)Sellinger, A.; Weiss, P. M.; Nguyen, A.; Lu, Y.; Assink, R. A.; Gong, W.; Brinker, C. J. Nature 1998, 394, 256-260.

26)Frye, G. C.; Ricco, A. J.; Martin, S. J.; Brinker, C. J. Characterization of the surface area and porosity of sol-gel films using saw devices; Brinker, C. J., Clark, D. E. and Ulrich, D. R., Ed.; Mat. Res. Soc.: Reno, Nevada, 1988; Vol. 121, pp 349-354.

27)Loy, D. A.; Carpenter, J. P.; Alam, T. M.; Shaltout, R.; Dorhout, P. K.; Greaves, J.; Small, J. H.; Shea, K. J. J. Am. Chem. Soc. 1999, 121(23), 5413-5425. 


\section{FIGURE CAPTIONS}

Figure 1. XRD of the uncalcined and calcined thin film mesophases prepared using ethylene-bridged silsesquioxane precursor $(\underline{1}$, with $\mathrm{n}=2)$ and CTAB $(6 \%)$, Brij-56 (4\%) or SDS (3\%) surfactants.

Figure 2. TEM micrograph of calcined bridged polysilsesquioxane thin film and particle mesophases prepared using (a) precursor (1) and CTAB (6\%); (b) precursor (1) and Brij56 (4\%); (c) precursor (2) and P123 (8\%); and (d) precursor ()ㅡ) and P123 (8\%).

Figure 3. Surface acoustic wave (SAW) based nitrogen sorption isotherms of the calcined thin film meosphases prepared using ethylene-bridged silsesquioxane precursor (1) and $\mathrm{CTAB}(6 \%)$ or Brij-56 (4\%) surfactants.

TABLE1 Properties of Calcined TEOS//( $\left.=\mathrm{Si}-\left(\mathrm{CH}_{2}\right)_{2}-\mathrm{Si} \equiv\right)$ Mesoporous Thin films Prepared with $4 \mathrm{wt} \%$ Brij-56 Surfactant

\begin{tabular}{|c|c|c|c|c|c|}
\hline $\begin{array}{c}\text { Framework } \\
\text { (TEOS:Silses } \\
\text { quioxane) }\end{array}$ & $\begin{array}{c}\text { Thickness } \\
(\AA)\end{array}$ & $\begin{array}{c}\text { Dielectric } \\
\text { Constant }\end{array}$ & Porosity & $\begin{array}{c}\text { Modulus } \\
(\mathbf{G P a})\end{array}$ & $\begin{array}{c}\text { Hardness } \\
(\mathbf{G P a})\end{array}$ \\
\hline $\begin{array}{c}\mathrm{TB}_{1} \\
(75: 25)\end{array}$ & 3135 & 2.15 & $56 \%$ & 3.5 & 0.35 \\
\hline $\begin{array}{c}\mathrm{TB}_{2} \\
(50: 50)\end{array}$ & 3154 & 2.13 & $53 \%$ & 3.7 & 0.39 \\
\hline $\begin{array}{c}\mathrm{TB}_{3} \\
(25: 75)\end{array}$ & 3015 & 1.98 & $56 \%$ & 4.3 & 0.48 \\
\hline
\end{tabular}




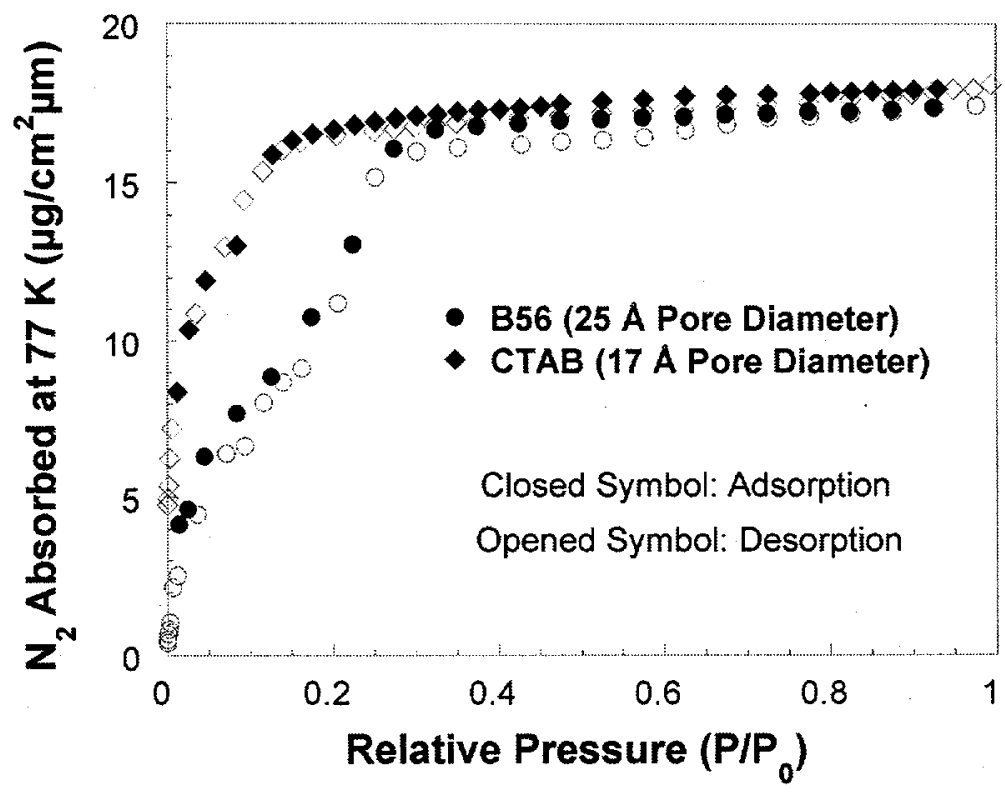



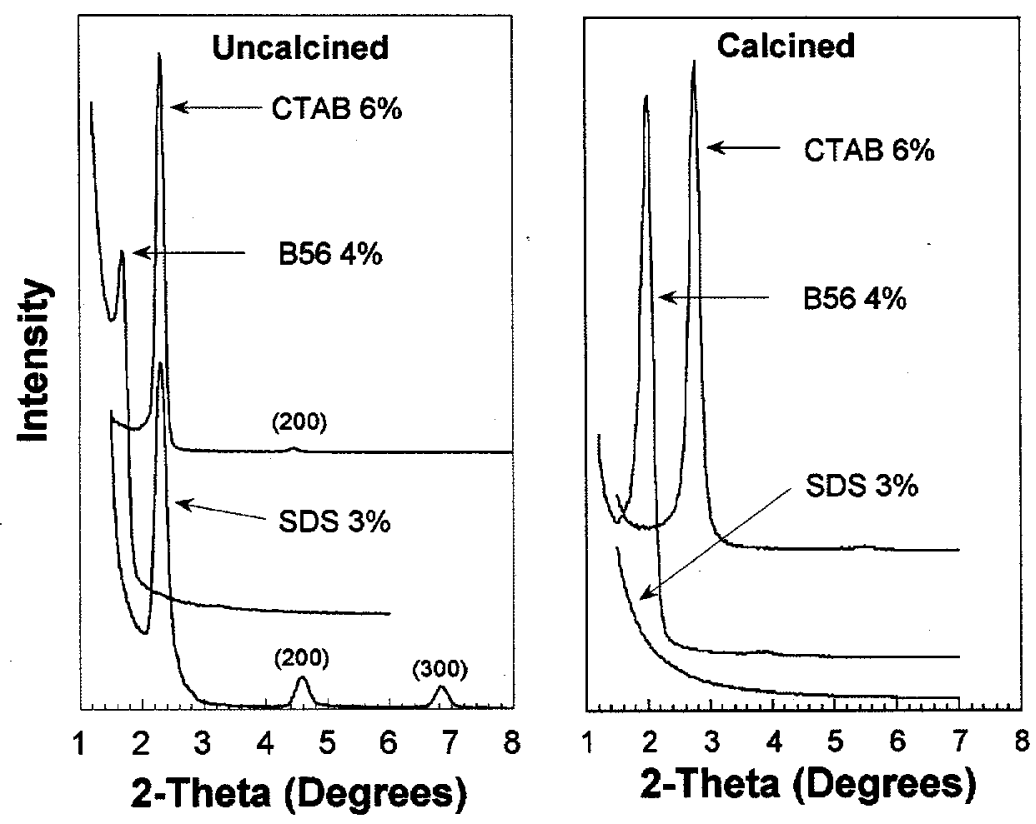

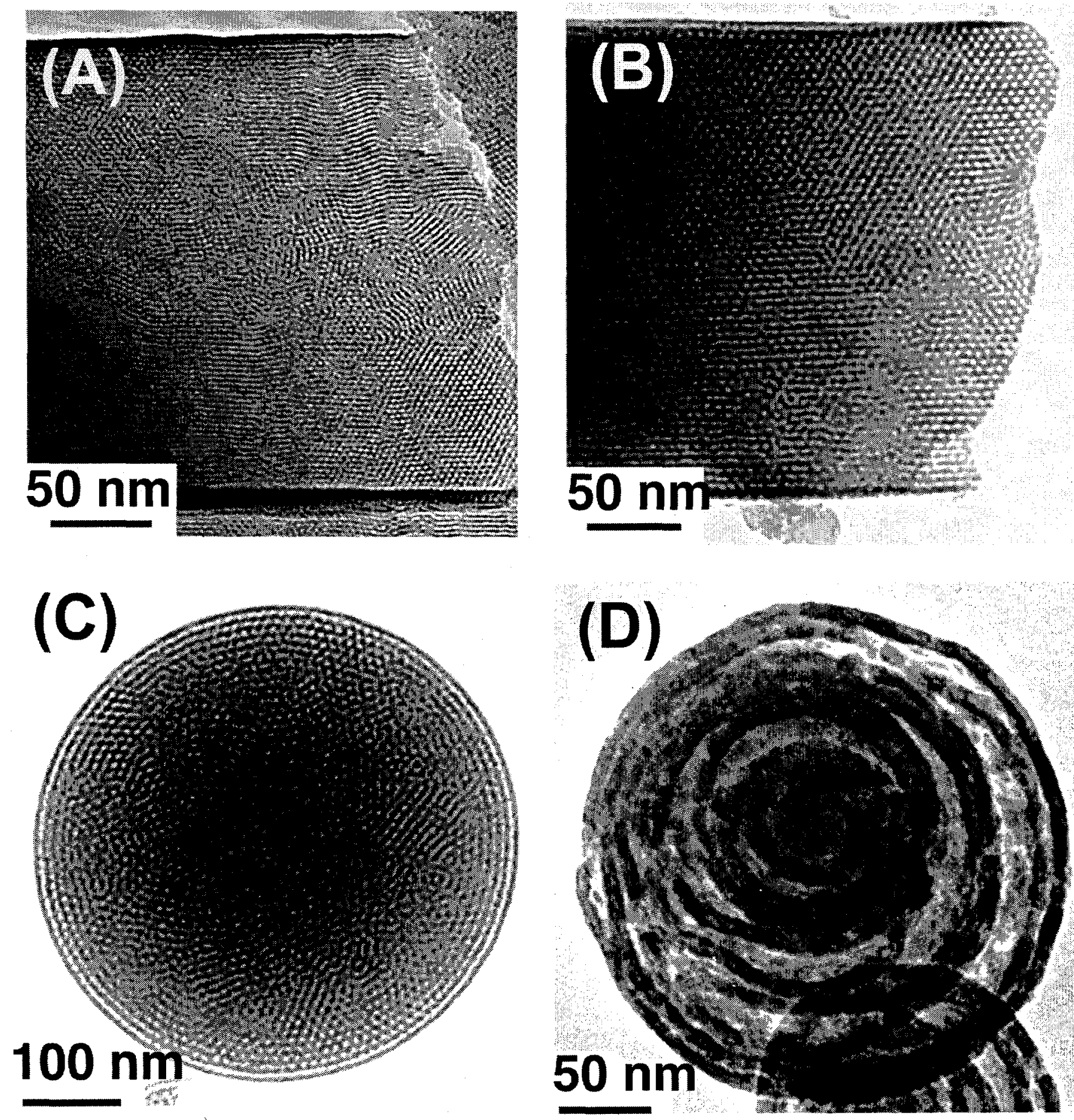